\title{
Room-Temperature Polycondensation of Dicarboxylic Acids and Diols Catalyzed by Water-Stable Lewis Acids
}

\author{
Akinori TAKASU, ${ }^{\dagger}$ Yoshitaka IIO, Taiki MIMURA, and Tadamichi HIRABAYASHI \\ Department of Environmental Technology and Urban Planning, Graduate School of Engineering, \\ Nagoya Institute of Technology, Gokiso-Cho, Showa-Ku, Nagoya 466-8555, Japan
}

(Received July 5, 2005; Accepted August 20, 2005; Published December 15, 2005)

\begin{abstract}
Room-temperature polycondensations of methylsuccinic acid (MSA) (at $35^{\circ} \mathrm{C}$ ), bromosuccinic acid (BSA), 2-bromoadipic acid (BAA) (at $\left.40^{\circ} \mathrm{C}\right)$, and citraconic acid (CA) (at $60^{\circ} \mathrm{C}$ ) with diols containing 1,3-propanediol (1,3-PD) and 1,4-butanediol (1,4-BD) were performed under reduced pressure $(0.3-30 \mathrm{mmHg})$ using scandium trifluoromethanesulfonate $\left[\mathrm{Sc}(\mathrm{OTf})_{3}\right]$, scandium trifluoromethanesulfonimide $\left[\mathrm{Sc}\left(\mathrm{NTf}_{2}\right)_{3}\right]$, and polymer-supported scandium trifluoromethanesulfonate (PS-Sc) to give poly(alkylene alkanoate)s with $M_{\mathrm{n}}=0.67 \times 10^{4}-1.41 \times 10^{4}\left(M_{\mathrm{w}} / M_{\mathrm{n}}=\right.$ 1.4-2.1) with quantitative yields. The catalysts are recovered quantitatively and reused. Room-temperature polycondensation made it possible to use thermally unstable monomers containing carbon-carbon double bond and bromo functionality. The atom-transfer radical polymerization (ATRP) of methyl methacrylate (MMA) $\left([\mathrm{M}]_{0} /\left[\mathrm{I}_{0}=10\right)\right.$ using poly(butylene succinate-co-butylene bromoadipate) [poly(BS-co-BBA)] $\left(M_{\mathrm{n}}=0.75 \times 10^{4}, M_{\mathrm{w}} / M_{\mathrm{n}}=2.0\right)$ as the macroinitiator and complex of $\mathrm{CuBr}$ and 1,1,4,7,10,10-hexamethyltriethylenetetramine (HMTETA) as the catalyst was carried out in anisole at $80^{\circ} \mathrm{C}$ for $10 \mathrm{~h}$ under nitrogen atmosphere to give polyester having PMMA side chains [ $M_{\mathrm{n}}=2.01 \times 10^{4}$ and $M_{\mathrm{w}} / M_{\mathrm{n}}=1.9,65 \%$ yield]. [DOI $10.1295 /$ polymj.37.946]

KEY WORDS Room-Temperature Polycondensation / Scandium Trifluoromethanesulfonate $\left[\mathrm{Sc}(\mathrm{OTf})_{3}\right]$ / Scandium Trifluoromethanesulfonimide [Sc $\left.\left(\mathrm{NTf}_{2}\right)_{3}\right]$ / Polymer-Supported Scandium Trifluoromethanesulfonate (PS-Sc) / Atom-Transfer Radical Polymerization (ATRP) / Citraconic Acid (CA) / Bromosuccinic Acid (BSA) /
\end{abstract}

Remarkable attention is paid to polymers that have potentials as biomaterials and environmentally-benign materials. Particularly, aliphatic polyesters including poly(ethylene succinate) (PES) and poly(butylene succinate) (PBS) would replace many conventional plastics in near future because of their biodegradability, acceptable mechanical strength, and comparable softening temperature to low density polyethylene and polystyrene. ${ }^{1}$ However, the syntheses require polycondensations of dicarboxylic acids and diols under severe conditions $\left(>250^{\circ} \mathrm{C}\right.$ under highly reduced pressure). ${ }^{2}$ Although some researchers reported that in situ enhancement of monomer (carboxylic acid) reactivity using active reagents made it possible to synthesize polyesters at/near room temperature, ${ }^{3}$ recent concern toward environmental problems prompted us to explore "ideal polycondensation system," taking (1) low temperature (2) avoiding organic solvent (3) atomic economy (4) lack of catalyst toxicity after use (5) catalyst recyclability and reuse. While direct polycondensation is considered to be the best way from these viewpoints, a survey of new Lewis acids had been difficult, ${ }^{4}$ because most Lewis acids are decomposed or deactivated by protic substances including carboxylic acids, alcohols, and water, which is not suitable for dehydration polycondensations. Applications of aliphatic polyesters will be further broadened when functional groups are incorporated into the polymer backbones. Room-temperature direct polycondensation promises not only saving heat energy but also extension of the range of monomers having chirality, functionality, and biological activity, because these monomers are labile under severe conditions.

As the catalyst, we focused on scandium catalysts because they are insensitive to protic compounds and they catalyze some reactions even in water because of the low hydrolysis constant ${ }^{5}$ and high exchange rate constant for substitution of inner-sphere water ligand, ${ }^{5 b}$ the catalysts can be quantitatively recovered after reactions and reused. As a preliminary result, we already reported room-temperature direct polycondensation of dicarboxylic acids with diols catalyzed by rare-earth trifluoromethanesulfonate ${ }^{6 a}$ and trifluoromethanesulfonimide ${ }^{6 \mathrm{~d}}$ to afford aliphatic polyesters with $M_{\mathrm{n}}$ of $>1.0 \times 10^{4}$.

In this paper, we describe one-step syntheses of aliphatic polyesters at/near room temperature, "room-temperature polycondensation ${ }^{7}$ " using waterstable catalysts, scandium trifluoromethanesulfonate

${ }^{\dagger}$ To whom correspondence should be addressed (Tel: +81-52-735-7159, Fax: +81-52-735-5342, E-mail: takasu.akinori@ nitech.ac.jp). 


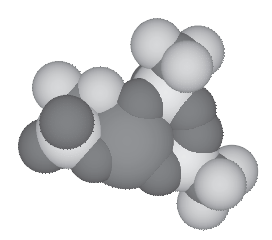

$\operatorname{Sc}(\mathbf{O T f})_{3}$

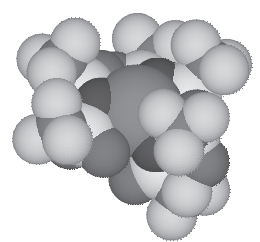

$\operatorname{Sc}\left(\mathbf{N T f}_{2}\right)_{3}$

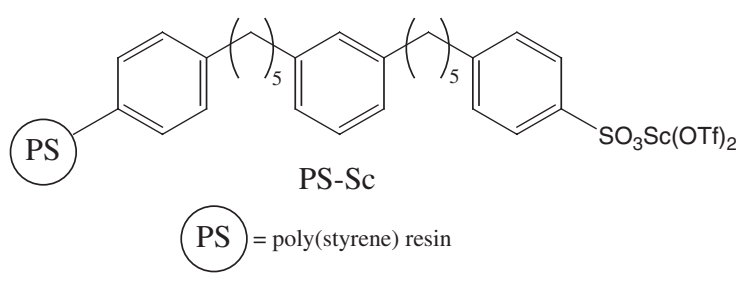

Figure 1. Molecular structure of scandium trifluoromethanesulfonate $\left[\mathrm{Sc}(\mathrm{OTf})_{3}\right]$, scandium trifluoromethanesulfonimide [Sc$\left.\left(\mathrm{NTf}_{2}\right)_{3}\right]$, and polymer-supported scandium trifluoromethanesulfonate (PS-Sc).

$\left[\mathrm{Sc}(\mathrm{OTf})_{3}\right]$, scandium trifluoromethanesulfonimide $\left[\mathrm{Sc}\left(\mathrm{NTf}_{2}\right)_{3}\right]$ (Figure 1). The solubility and stability in water realized recovery by extraction with water and subsequent reuse. Moreover procedure for the recovery was simplified by polymer-supported scandium trifluoromethanesulfonate (PS-Sc). Room-temperature polycondensation of dicarboxylic acid containing $\mathrm{C}=\mathrm{C}$ double bond or bromo functionality produced polyesters having reacting groups. Room-temperature polycondensation combines with atom transfer radical polymerization (ATRP) using poly(butylene bromosuccinate) (PBBS) and poly(butylene succinate-cobutylene bromoadipate) [poly(BS-co-BBA)] as the macroinitiators to synthesize polyesters having poly(methyl methacrylate) (PMMA) side chains via grafting from techniques (Scheme 3).

\section{EXPERIMENTAL}

\section{Materials}

Scandium triacetate $\left[\mathrm{Sc}(\mathrm{OAc})_{3}\right]$ was purchased from Kanto Chemical Co., Inc. (Tokyo, Japan). Bromosuccinic acid (BSA), 1,1,4,7,10,10-hexamethyltriethylenetetramine (HMTETA), trifluoromethanesulfonimide $\left[\mathrm{HN}\left(\mathrm{CF}_{3} \mathrm{SO}_{2}\right)_{2}\right]$, polymer-supported scandium trifluoromethanesulfonate (PS-Sc) (scandium content: $0.64 \mathrm{mmol} / \mathrm{g}$ ), methylsuccinic acid (MSA) were purchased from Sigma Aldrich. Sc(OTf $)_{3}$ and citraconic acid (CA) were obtained from Tokyo Kasei Co. (Tokyo, Japan) and Wako Pure Chemical Co. (Osaka, Japan), respectively. Succinic acid (SA), methyl methacrylate (MMA), cuprous (I) bromide (CuBr), 1,3-PD, and 1,4-BD were purchased from Nacalai Tesque (Kyoto, Japan). 2-Bromoadipic acid (BAA) was prepared in our laboratory according to Starostin's re- port. ${ }^{8}$ Anisole, chloroform, diethyl ether, methanol, ethanol, hexane, ethyl acetate, acetic acid, and water used were purified by distillation before use.

\section{Preparation of $\mathrm{Sc}\left(\mathrm{NTf}_{2}\right)_{3}$}

The preparation was carried out according to literature. ${ }^{9}$ In a flask equipped with reflux condenser, Sc$(\mathrm{OAc})_{3}(1.0 \mathrm{~g}, 4.5 \mathrm{mmol}), \mathrm{HNTf}_{2}(3.3 \mathrm{~g}, 13.6 \mathrm{mmol})$, and $24 \mathrm{~mL}$ of water were taken. The mixture was stirred at $100^{\circ} \mathrm{C}$ for $5 \mathrm{~h}$ and evaporated to give white solid. The reaction was monitored by TLC measurement $\left(R_{\mathrm{f}}=0.06\right.$ in methanol $)$ and the structure was confirmed by ${ }^{13} \mathrm{C}$ NMR measurement. ${ }^{13} \mathrm{C}$ NMR (50 $\mathrm{MHz}, \mathrm{CDCl}_{3}, \delta$, ppm) for $\mathrm{Sc}\left(\mathrm{NTf}_{2}\right) \cdot \mathrm{CH}_{3} \mathrm{COOH}: 21.1$ $\left(\mathrm{CH}_{3} \mathrm{CO}\right), 119.5\left(\mathrm{SO}_{2} \mathrm{CF}_{3}, \mathrm{q}, J_{\mathrm{CF}}=318 \mathrm{~Hz}\right), 178.3$ $\left(\mathrm{CH}_{3} \mathrm{CO}\right)$.

\section{Model Reaction}

In a flask, esterification of acetic acid $(1.44 \mathrm{~g}, 24$ $\mathrm{mmol})$ and ethanol $(0.55 \mathrm{~g}, 12 \mathrm{mmol})$ are catalyzed by PS-Sc $(0.38 \mathrm{~g}, 0.24 \mathrm{mmol})$ in the absence and presence of methyl acetate $(1.79 \mathrm{~g}, 24 \mathrm{mmol})$. The reaction condition was at $27^{\circ} \mathrm{C}$ for $7 \mathrm{~h}$. The conversion was calculated by ${ }^{1} \mathrm{H}$ NMR intensity ratio.

\section{Room-Temperature Polycondensation of MSA with Diols}

For poly(butylene methylsuccinate): A typical polycondensation procedure is as follows. In a threenecked tube, MSA $(7.0 \mathrm{mmol}), 1,4-\mathrm{BD}(7.0 \mathrm{mmol})$, and $\mathrm{Sc}\left(\mathrm{NTf}_{2}\right)_{3}(0.3 \mathrm{~mol} \%)$ were mixed and stirred at room temperature for $1 \mathrm{~h}$. The polycondensation started at $35^{\circ} \mathrm{C}$ under $30 \mathrm{mmHg}$. After $10 \mathrm{~h}$, the reduced pressure gradually increased to $0.3-3 \mathrm{mmHg}$ and kept for $80 \mathrm{~h}$ to complete the condensation. After the reaction, yield of the polyester was calculated by subtraction weight of the catalyst from the isolated material (96\% yield, run 11 in Table I). After reprecipitation using $\mathrm{CHCl}_{3}$ and diethyl ether, the yield was $85 \%$. ${ }^{1} \mathrm{H}$ NMR $\left(200 \mathrm{MHz}, \mathrm{CDCl}_{3}, \delta, \mathrm{ppm}\right): 1.20-1.24(\mathrm{CH}-$ $\left.\mathrm{CH}_{3}\right), 1.69-1.71\left(\mathrm{OCH}_{2} \mathrm{CH}_{2}\right), 2.34-2.45$ and 2.67$2.82\left(\mathrm{CHCH}_{2}\right), 2.85-2.96\left(\mathrm{CHCH}_{2}\right), 4.11\left(\mathrm{COOCH}_{2}\right)$. ${ }^{13} \mathrm{C}$ NMR $\left(50 \mathrm{MHz}, \mathrm{CDCl}_{3}, \delta, \mathrm{ppm}\right): 17.0\left(\mathrm{CHCH}_{3}\right)$, $25.2\left(\mathrm{OCH}_{2} \mathrm{CH}_{2}\right), 35.8\left(\mathrm{CHCH}_{2}\right), 37.5\left(\mathrm{CHCH}_{2}\right), 64.1$ $\left(\mathrm{OCH}_{2} \mathrm{CH}_{2}\right), 171.8$ and $175.2\left(\mathrm{COOCH}_{2}\right)$. IR $(\mathrm{KBr}$ disk, $\left.\mathrm{cm}^{-1}\right): 2965\left(v_{\mathrm{C}-\mathrm{H}}\right), 1734\left[v_{\mathrm{C}=\mathrm{O}}(\right.$ ester $\left.)\right], 1464$ $\left(\delta_{\mathrm{C}-\mathrm{H}}\right), 1277$ and $1169\left[v_{\mathrm{C}-\mathrm{O}}(\right.$ ester $\left.)\right]$.

\section{Catalyst Recovery}

Procedure of recovery of the catalyst is as follows. The reaction mixture was resolved in $\mathrm{CHCl}_{3}(3 \mathrm{~mL})$ and washed with water $(5 \mathrm{~mL})$. The aqueous layer was evaporated to give recovered $\mathrm{Sc}(\mathrm{OTf})_{3}(95 \%$ yield). $\mathrm{Sc}\left(\mathrm{NTf}_{2}\right)_{3}$ could be also recovered by similar procedure using $\mathrm{CHCl}_{3} / n$-hexane $(1: 1, \mathrm{v} / \mathrm{v})$ instead 
of $\mathrm{CHCl}_{3}$ (recovery 90\%). For recovery of PS-Sc, the reaction mixture was dissolved in ethyl acetate and simply filtered (recovery $>99 \%$ ).

Polycondensation of Bromosuccinic acid with 1,4-BD

Polycondensation of BSA and 1,4-BD was carried out in a similar manner of that for polycondensation of MSA with 1,4-BD. ${ }^{1} \mathrm{H}$ NMR $\left(200 \mathrm{MHz}, \mathrm{CDCl}_{3}, \delta\right.$, ppm): 1.71-1.80 $\left(\mathrm{OCH}_{2} \mathrm{CH}_{2}\right), 2.93-3.05$ and 3.22$3.35\left(\mathrm{CH}_{2} \mathrm{CHBr}\right), 4.16\left(\mathrm{CH}_{2} \mathrm{COOCH}_{2}\right), 4.23(\mathrm{CHBr}-$ $\left.\mathrm{COOCH}_{2}\right) .{ }^{13} \mathrm{C}$ NMR $\left(50 \mathrm{MHz}, \mathrm{CDCl}_{3}, \delta, \mathrm{ppm}\right): 25.0$ $\left(\mathrm{OCH}_{2} \mathrm{CH}_{2}\right), 38.0\left(\mathrm{CH}_{2} \mathrm{CHBr}\right), 39.6\left(\mathrm{CH}_{2} \mathrm{CHBr}\right), 64.5$ and $65.5\left(\mathrm{OCH}_{2} \mathrm{CH}_{2}\right), 169.0$ and $169.6\left(\mathrm{COOCH}_{2}\right)$. IR $\left(\mathrm{KBr}\right.$ disk, $\left.\mathrm{cm}^{-1}\right): 2960\left(v_{\mathrm{C}-\mathrm{H}}\right), 1737$ [ $v_{\mathrm{C}=\mathrm{O}}($ ester $\left.)\right]$, 1467 and $1395\left(\delta_{\mathrm{C}-\mathrm{H}}\right), 1334\left(\delta_{\mathrm{C}-\mathrm{Br}}\right), 1260$ and 1164 $\left[v_{\mathrm{C}-\mathrm{O}}(\right.$ ester $\left.)\right]$.

\section{Grafting of MMA from Polyester Containing Pendant Bromo Functionality Using ATRP Technique}

A typical ATRP procedure is as follows. Poly(BSco-BBA) ( $0.2 \mathrm{mmol}$ of bromo content), MMA (2.0 $\mathrm{mmol}), \mathrm{CuBr}(0.2 \mathrm{mmol}), 1,1,4,7,10,10$-hexamethyltriethylenetetramine (HMTETA) $(0.2 \mathrm{mmol})$ and $6 \mathrm{~mL}$ of anisole were weighed into a glass tube equipped with stopcock under nitrogen atmosphere. The solvent was frozen by liquid nitrogen, the stopcock was opened to vacuum and kept for $10 \mathrm{~min}$ in order to remove the air completely. The tube was sealed under reduced pressure and placed in an oil bath kept at $80^{\circ} \mathrm{C}$ for $10 \mathrm{~h}$. After the reaction, the contents were dropped in excess methanol. The polymeric material was purified by reprecipitation using chloroform and methanol, the yield was $65 \%$ (trunk base). ${ }^{1} \mathrm{H}$ NMR (200 $\mathrm{MHz}, \mathrm{CDCl}_{3}, \delta$, ppm): 0.85, 1.03, $1.26\left(\mathrm{CCH}_{3}\right), 1.32-$ 2.21 [ $\mathrm{CH}_{2}$ in MMA, $\mathrm{OCH}_{2} \mathrm{CH}_{2}, \mathrm{COCH}_{2} \mathrm{CH}_{2} \mathrm{CH}_{2} \mathrm{CH}-$ (PMMA)CO, $\mathrm{COCH}_{2} \mathrm{CH}_{2} \mathrm{CH}_{2} \mathrm{CHBrCO}$, 2.21-2.44 [ $\mathrm{COCH}_{2} \mathrm{CH}_{2} \mathrm{CH}_{2} \mathrm{CH}$ (PMMA)CO, $\mathrm{COCH}_{2} \mathrm{CH}_{2} \mathrm{CH}_{2}$ $\mathrm{CHBrCO}], 2.63\left(\mathrm{COCH}_{2} \mathrm{CH}_{2} \mathrm{CO}\right), 3.61\left(\mathrm{COOCH}_{3}\right)$, 4.00-4.28 ( $\left.\mathrm{OCH}_{2} \mathrm{CH}_{2}, \mathrm{COCH}_{2} \mathrm{CH}_{2} \mathrm{CH}_{2} \mathrm{CHBrCO}\right)$. IR $\left(\mathrm{KBr}\right.$ disk, $\left.\mathrm{cm}^{-1}\right): 2953\left(v_{\mathrm{C}-\mathrm{H}}\right), 1732$ [ $v_{\mathrm{C}=\mathrm{O}}($ ester $)$ ], 1450 and $1392\left(\delta_{\mathrm{C}-\mathrm{H}}\right), 1355\left(\delta_{\mathrm{C}-\mathrm{Br}}\right), 1243$ and 1156 $\left[v_{\mathrm{C}-\mathrm{O}}(\right.$ ester $\left.)\right]$.

\section{Measurements}

FT/IR spectra were recorded in $\mathrm{KBr}$ disks using a JASCO FT/IR-430 spectrometer. ${ }^{1} \mathrm{H}$ and ${ }^{13} \mathrm{C}$ NMR spectra were measured at $27^{\circ} \mathrm{C}$ using a Bruker DPX200 spectrometer (200 MHz for ${ }^{1} \mathrm{H}$ NMR). All chemical shifts were expressed as $\delta$ downfield from tetramethylsilane (TMS). Number average molecular weights $\left(M_{\mathrm{n}}\right)$ and the polydispersity indexes $\left(M_{\mathrm{w}} /\right.$ $M_{\mathrm{n}}$ ) of polymers were estimated by size exclusion chromatography (SEC) calibrated with polystyrene standards using a pump system of Tosoh DP8020 with a RI (Tosoh RI-8020) detector and Tosoh G2000,
3000, 4000, and 5000-HXL columns (eluent, chloroform; flow rate, $1.0 \mathrm{~mL} / \mathrm{min}$; temperature, $40^{\circ} \mathrm{C}$ ).

\section{RESULTS AND DISCUSSION}

As a model reaction of the polyesterification, the direct esterification of ethanol using 2 equimolar amounts of acetic acid was carried out in bulk using $1.0 \mathrm{~mol} \%$ of $\mathrm{Sc}(\mathrm{OTf})_{3}, \mathrm{Sc}\left(\mathrm{NTf}_{2}\right)_{3}$ and PS-Sc at $27^{\circ} \mathrm{C}$ for $7 \mathrm{~h}$ without removing water. The conversions determined by ${ }^{1} \mathrm{H}$ NMR were 89,72 , and $41 \%$ respectively. On the other hand, the esterification scarcely occurs without the catalysts. Although one may envision that esterification proceeds through the acid anhydride, we could not observe any peaks ascribed to acetic anhydride in the ${ }^{1} \mathrm{H}$ NMR measurement. On the basis of the model reaction, we confirmed that these catalyzed the direct esterification of carboxylic acids and alcohols at room temperature. To clarify which reacts with ethanol faster in the presence of the scandium catalysts, we examined chemoselective esterification for a 1:1 mixture of acetic acid or methyl acetate (Scheme 1). Surprisingly, ethanol reacted with acetic acid chemoselectively in the presence of Sc$(\mathrm{OTf})_{3}(90 \%), \mathrm{Sc}\left[(\mathrm{NTf})_{2}\right]_{3}(92 \%)$ and PS-Sc $(97 \%)$, respectively, in which PS-Sc showed the highest selectivity. From the results, we could expect the polycondensation proceed minimizing transesterification.

Bulk polycondensations of methylsuccinic acid (MSA) and diols, 1,4-BD $(\mathrm{n}=4)$ and 1,3-PD $(\mathrm{n}=$ $3)$, were carried out under reduced pressure $(0.3-$ $30 \mathrm{mmHg}$ ) using $\mathrm{Sc}(\mathrm{OTf})_{3}$ at $35^{\circ} \mathrm{C}$ (Scheme 2 and Table I). The number-average molecular weights $\left(M_{\mathrm{n}} \mathrm{s}\right)$ were estimated by size exclusion chromatography (SEC) using $\mathrm{CHCl}_{3}$ as the eluent (polystyrene standards). In all runs, white polymeric solids were obtained which were soluble in chloroform, tetrahydrofuran (THF), and acetonitrile. Interestingly, the direct polycondensation proceeded even at room temperature $\left(35^{\circ} \mathrm{C}\right)$ to afford poly(butylene methylsuccinate) (PBMS) with $M_{\mathrm{n}}$ of $1.2 \times 10^{4}$ for $96 \mathrm{~h}$ in the presence of $1.4 \mathrm{~mol} \%$ catalyst (94\% yield, run 4 ), i.e., room-temperature direct polyesterification was established to give the polyester $\left(M_{\mathrm{n}}=1.0 \times 10^{4}\right)$ by a one-step procedure. In the absence of catalyst, the polyester was not obtained $\left(M_{\mathrm{n}}=400\right.$, run 5). Using trifluoromethanesulfonic acid (TfOH) as the Brønsted acid (run 6), the $M_{\mathrm{n}}$ was quite low $\left(M_{\mathrm{n}}=0.3 \times 10^{4}\right)$ compared with that catalyzed by $\mathrm{Sc}(\mathrm{OTf})_{3}$. Surprisingly, the polycondensation using $1.0 \mathrm{~mol} \% \mathrm{Sc}(\mathrm{OTf})_{3}$ was much superior to that using same amount of $\mathrm{HfCl}_{4}(\mathrm{THF})_{2}$ (runs 3 and 7). As most Lewis acids are sensitive to protic substances, the catalytic activities are lowered during dehydration polycondensation. It seems that the $\mathrm{Sc}(\mathrm{OTf})_{3}$ catalyzed the direct poly- 


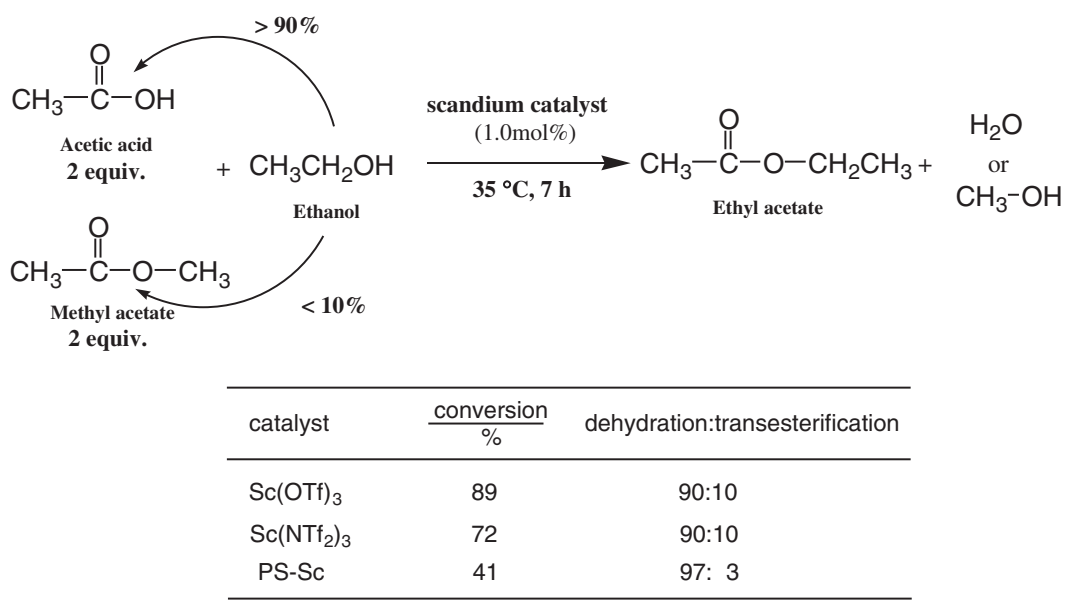

Scheme 1. Model reaction of carboxylic acid and alcohol in presence of carboxylic acid methyl ester.<smiles>CC(CC(=O)O)C(=O)O</smiles>

methylsuccinic acid (MSA)
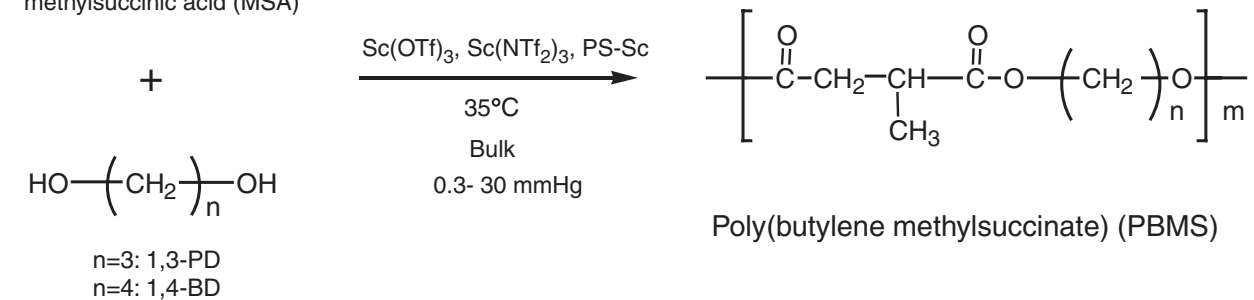

Poly(butylene methylsuccinate) (PBMS)

Scheme 2. Room-temperature direct polycondensation of dicarboxylic acids with diols.

Table I. Room-Temperature Direct Polycondensation of Dicarboxylic Acids and 1,4-BD

\begin{tabular}{|c|c|c|c|c|c|c|c|}
\hline Run & $\begin{array}{c}\text { Dicarboxylic } \\
\text { Acids }\end{array}$ & $\begin{array}{l}\text { Catalyst } \\
(\mathrm{mol} \%)\end{array}$ & $\begin{array}{l}\text { Temp. } \\
\left({ }^{\circ} \mathrm{C}\right)\end{array}$ & $\begin{array}{l}\text { Time } \\
\text { (h) }\end{array}$ & $\begin{array}{l}\text { Yield } \\
(\%)\end{array}$ & $M_{\mathrm{n}}^{\mathrm{b}} \times 10^{-4}$ & $M_{\mathrm{w}} / M_{\mathrm{n}}^{\mathrm{b}}$ \\
\hline 1 & $\mathrm{MSA}^{\mathrm{c}}$ & $\mathrm{Sc}(\mathrm{OTf})_{3}(0.3)$ & 35 & 110 & $95^{\mathrm{d}}$ & 0.59 & 1.6 \\
\hline 2 & $\mathrm{MSA}^{\mathrm{c}}$ & $\mathrm{Sc}(\mathrm{OTf})_{3}(0.5)$ & 35 & 110 & $88^{\mathrm{d}}$ & 0.54 & 1.6 \\
\hline 3 & $\mathrm{MSA}^{\mathrm{c}}$ & $\mathrm{Sc}(\mathrm{OTf})_{3}(1.0)$ & 35 & 110 & $99^{\mathrm{d}}$ & 0.97 & 1.5 \\
\hline 4 & $\mathrm{MSA}^{\mathrm{c}}$ & $\mathrm{Sc}(\mathrm{OTf})_{3}(1.4)$ & 35 & 96 & $94^{\mathrm{d}}$ & 1.24 & 1.4 \\
\hline 5 & $\mathrm{MSA}^{\mathrm{c}}$ & blank & 35 & 99 & $97^{\mathrm{d}}$ & 0.04 & 1.3 \\
\hline 6 & $\mathrm{MSA}^{\mathrm{c}}$ & TfOH (1.0) & 35 & 99 & $91^{\mathrm{d}}$ & 0.30 & 1.7 \\
\hline 7 & $\mathrm{MSA}^{\mathrm{c}}$ & $\mathrm{HfCl}_{4}(\mathrm{THF})_{2}(1.0)$ & 35 & 70 & $92^{\mathrm{d}}$ & 0.11 & 1.3 \\
\hline 8 & $\mathrm{SA}^{\mathrm{e}}$ & $\mathrm{Sc}(\mathrm{OTf})_{3}(1.0)$ & 120 & 5 & $85^{\mathrm{f}}$ & 1.13 & 1.7 \\
\hline 9 & $\mathrm{SA}^{\mathrm{e}}$ & $\mathrm{Sc}(\mathrm{OTf})_{3}(0.1)$ & 160 & 10 & $83^{\mathrm{f}}$ & 2.09 & 1.5 \\
\hline 10 & $\mathrm{SA}^{\mathrm{e}}$ & $\mathrm{Sc}(\mathrm{OTf})_{3}(0.1)$ & 180 & 10 & $85^{\mathrm{f}}$ & 3.07 & 1.4 \\
\hline 11 & $\mathrm{MSA}^{\mathrm{c}}$ & $\mathrm{Sc}\left(\mathrm{NTf}_{2}\right)_{3}(0.3)$ & 35 & 90 & $96^{d}\left(85 \%^{f}\right)$ & 1.22 & 1.5 \\
\hline 12 & $\mathrm{MSA}^{\mathrm{c}}$ & $\mathrm{Sc}\left(\mathrm{NTf}_{2}\right)_{3}(0.5)$ & 35 & 60 & $97^{\mathrm{d}}$ & 1.00 & 1.7 \\
\hline 13 & $\mathrm{MSA}^{\mathrm{c}}$ & $\operatorname{Sc}\left(\mathrm{NTf}_{2}\right)_{3}(1.0)$ & 35 & 70 & $92^{\mathrm{d}}$ & 0.90 & 1.5 \\
\hline 14 & $\mathrm{MSA}^{\mathrm{c}}$ & PS-Sc (1.0) & 80 & 24 & $90^{\mathrm{d}}$ & 0.34 & 1.9 \\
\hline 15 & $\mathrm{MSA}^{\mathrm{c}}$ & PS-Sc (1.0) & 120 & 72 & $73^{\mathrm{d}}$ & 1.04 & 1.5 \\
\hline 16 & $\mathrm{MSA}^{\mathrm{c}}$ & $\mathrm{Sc}(\mathrm{OTf})_{3}{ }^{\mathrm{g}}(1.4)$ & 35 & 104 & $93^{\mathrm{d}}$ & 0.68 & 1.4 \\
\hline 17 & $\mathrm{MSA}^{\mathrm{c}}$ & $\mathrm{Sc}\left(\mathrm{NTf}_{2}\right)_{3} \mathrm{~g}(0.3)$ & 35 & 110 & $98^{\mathrm{d}}$ & 0.93 & 1.5 \\
\hline 18 & $\mathrm{MSA}^{\mathrm{c}}$ & PS-Sc ${ }^{\mathrm{g}}(1.0)$ & 120 & 72 & $70^{\mathrm{d}}$ & 0.68 & 1.5 \\
\hline
\end{tabular}

${ }^{\mathrm{a}}$ All runs are performed by bulk (melt) polycondensation under reduced pressure $(0.3-30 \mathrm{mmHg})$. ${ }^{\mathrm{b}}$ Determined by SEC measurement in $\mathrm{CHCl}_{3}$ relative to poly(styrene). ${ }^{\mathrm{c}}$ Methylsuccinic acid. ${ }^{\mathrm{d}}$ Without reprecipitation. ${ }^{\mathrm{e}}$ Succinic acid. ${ }^{\mathrm{f}}$ After reprecipitation using $\mathrm{CHCl}_{3}$ and hexane. ${ }^{g}$ Recovered catalyst. 


\section{A. TAKASU et al.}

Table II. Direct Polycondensation of Citraconic Acid (CA) and 1,4-BD ${ }^{\mathrm{a}}$

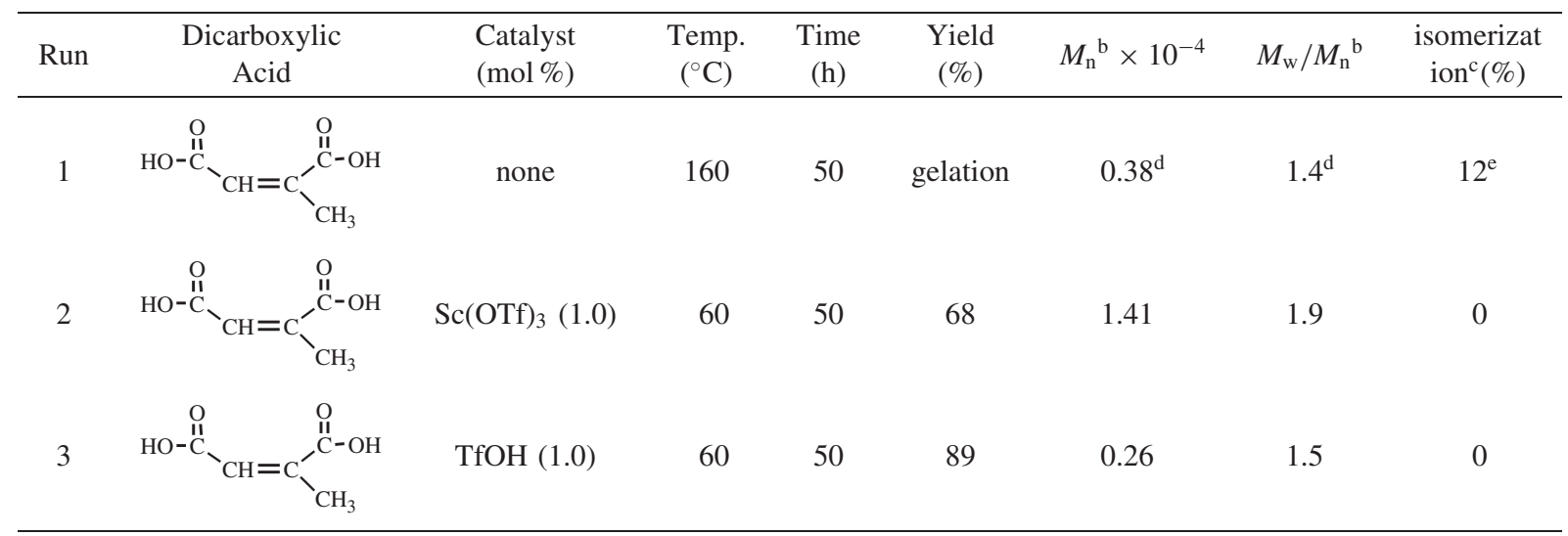

${ }^{a}$ All runs are performed by bulk (melt) polycondensation under reduced pressure $(0.3-30 \mathrm{mmHg})$. ${ }^{\mathrm{b}}$ Determined by SEC measurement in $\mathrm{CHCl}_{3}$ relative to poly(styrene). ${ }^{\mathrm{c}}$ Determined by ${ }^{1} \mathrm{H} \mathrm{NMR}$ in $\mathrm{CDCl}_{3}$. ${ }^{\mathrm{d}}$ Soluble part in THF. ${ }^{\mathrm{e}}$ Soluble part in $\mathrm{CDCl}_{3}$.

condensation effectively because of high activity, resistance to water, leading to high turnover frequency (TON). In the polycondensation of MSA with 1,3$\mathrm{PD}$, the polyesterification proceeded chemoselectively (without etherification) to give the corresponding polyester with $M_{\mathrm{n}}=0.7 \times 10^{4}$ for $110 \mathrm{~h}$. On the other hand, at $80^{\circ} \mathrm{C}$, etherification (9\%) as well as esterification $(91 \%)$ occurred to give oligo(ester-ether) [69\% yield (after reprecipitation), $M_{\mathrm{n}}=0.65 \times 10^{4}, M_{\mathrm{n}} /$ $\left.M_{\mathrm{n}}=1.4\right]{ }^{6 \mathrm{a}}$ The improved chemoselectivity was ascribed to the lower condensation temperature.

The $\mathrm{Sc}(\mathrm{OTf})_{3}$ catalyzed-polycondensations of SA and 1,4-BD were also performed to synthesize PBS (runs $8-10$ ). For the polymerization at $120^{\circ} \mathrm{C}$ above the $T_{\mathrm{m}}$, melt polycondensation using $1.0 \mathrm{~mol} \%$ catalyst could be achieved to give PBS with a $M_{\mathrm{n}}$ of $1.13 \times$ $10^{4}$ (85\% yield, run 8$)$. $\mathrm{Sc}(\mathrm{OTf})_{3}$ catalyzes the polycondensation of succinic acid with 1,4-butanediol at a lower temperature compared with those previously reported. ${ }^{2,4}$ The temperature was important for synthesis of higher molecular weight polyester. The polycondensation at 160 and $180^{\circ} \mathrm{C}$ for $10 \mathrm{~h}$ gave PBS with $M_{\mathrm{n}}$ of $2.09 \times 10^{4}\left(M_{\mathrm{w}} / M_{\mathrm{n}}=1.4_{9}\right)$ and $3.07 \times$ $10^{4}\left(M_{\mathrm{w}} / M_{\mathrm{n}}=1.4_{3}\right)$, respectively, even in the presence of $0.1 \mathrm{~mol} \%$ catalyst (runs 9 and 10 ).

Scandium trifluoromethanesulfonimide $\left[\mathrm{Sc}\left(\mathrm{NTf}_{2}\right)_{3}\right]$ is also known to be air stable and powerful Lewis acid, ${ }^{9}$ because it has higher fluorine content (Figure 1). In order to decrease the catalyst amount required for the polyesterification, $\mathrm{Sc}\left(\mathrm{NTf}_{2}\right)_{3}$-catalyzed direct polyesterification of MSA and 1,4-BD was carried out at $35^{\circ} \mathrm{C}$ (run 11-13). The catalytic activity was higher than that of $\mathrm{Sc}(\mathrm{OTf})_{3}$ in this polyesterification. Using $0.3 \mathrm{~mol} \%$ of $\mathrm{Sc}\left(\mathrm{NTf}_{2}\right)_{3}$, we could synthesize poly(butylene methylsuccinate) with $M_{\mathrm{n}}$ of $1.2 \times 10^{4}$. The molecular weight was higher than that using same amount of $\mathrm{Sc}(\mathrm{OTf})_{3}\left(0.59 \times 10^{4}\right.$, run 1). Using the
SEC data $\left(M_{\mathrm{n}}\right)$, calculated TON in this system is $160(\mathrm{~mol} / \mathrm{mol})$, which is superior to that using 0.3 mol\% of $\mathrm{Sc}(\mathrm{OTf})_{3}$ (TON: 150). As to molecular weight distribution $\left(M_{\mathrm{w}} / M_{\mathrm{n}}\right)$, the distributions are relatively narrow (1.4-1.7). The results supported that the polyesterification proceeded suppressing transesterification expectedly.

$\mathrm{Sc}(\mathrm{OTf})_{3}$ and $\mathrm{Sc}\left(\mathrm{NTf}_{2}\right)_{3}$ used in this study were easily recovered by solubilization in $\mathrm{CHCl}_{3}$ or $\mathrm{CHCl}_{3} /$ hexane $(1 / 1, \mathrm{v} / \mathrm{v})$ and successive extraction with water $\left[95 \%\right.$ for $\mathrm{Sc}(\mathrm{OTf})_{3}, 90 \%$ for $\left.\mathrm{Sc}\left(\mathrm{NTf}_{2}\right)_{3}\right]$. Direct polycondensation of MSA and 1,4-BD using the recovered catalysts gave polyesters with $M_{\mathrm{n}}$ of $0.68 \times 10^{4}$ for $104 \mathrm{~h}\left(M_{\mathrm{w}} / M_{\mathrm{n}}=1.4,93 \%\right.$ yield, run $16)$ and $M_{\mathrm{n}}$ of $0.93 \times 10^{4}$ for $110 \mathrm{~h}\left(M_{\mathrm{w}} / M_{\mathrm{n}}=1.5\right.$, $98 \%$ yield, run 17), respectively.

Polymer-supported scandium trifluoromethanesulfonate (PS-Sc) (Figure 1) is known to show high activity in water and can be easily recovered and reused. ${ }^{10}$ Polycondensation of MSA and 1,4-BD at $120^{\circ} \mathrm{C}$ occurred and afforded PBMS with $M_{\mathrm{n}}$ of $1.04 \times 10^{4}$ $\left(M_{\mathrm{w}} / M_{\mathrm{n}}=1.5\right)$ for $72 \mathrm{~h}(73 \%$ yield, run 15 in Table I), while the polycondensation at $80^{\circ} \mathrm{C}$ gave the polyester with $M_{\mathrm{n}}$ of $0.34 \times 10^{4}$. PS-Sc was actually recovered after the polycondensation by simple filtration and reused. The recovery was quantitative $(>99 \%)$ and remarkable loss of activity in the polycondensation was not confirmed. $70 \%$ yield was attained using $1.0 \%$ of the recovered PS-Sc (run 18), although a slight decrease in the $M_{\mathrm{n}}\left(0.68 \times 10^{4}\right)$ was confirmed.

\section{Room-Temperature Polycondensation of Dicarboxylic Acid Having Functionality}

As another example to illustrate the mildness of the polycondensation, we present the polycondensation using monomer containing carbon-carbon double bond, citraconic acid (Table II). The structure was 
Table III. Direct Polycondensation of Dicarboxylic Acid Having Bromo Functionality and 1,4-BD

\begin{tabular}{ccccccccc}
\hline Run & $\begin{array}{c}\text { Dicarboxylic } \\
\text { Acid }\end{array}$ & $\begin{array}{c}\text { Catalyst } \\
(\text { mol \%) }\end{array}$ & $\begin{array}{c}\text { Temp. } \\
\left({ }^{\circ} \mathrm{C}\right)\end{array}$ & $\begin{array}{c}\text { Time } \\
(\mathrm{h})\end{array}$ & $\begin{array}{c}\text { Yield }^{\mathrm{b}} \\
(\%)\end{array}$ & $M_{\mathrm{n}}{ }^{\mathrm{c}} \times 10^{-4}$ & $M_{\mathrm{w}} / M_{\mathrm{n}}{ }^{\mathrm{c}}$ & $\begin{array}{c}\text { Dehydro- } \\
\text { bromination }^{\mathrm{d}}(\%)\end{array}$ \\
\hline 1 & $\mathrm{BSA}^{\mathrm{e}}$ & $\mathrm{Sc}(\mathrm{OTf})_{3}(1.4)$ & 180 & 24 & 49 & 1.43 & 2.9 & 99 \\
2 & $\mathrm{BSA}^{\mathrm{e}}$ & $\mathrm{Sc}(\mathrm{OTf})_{3}(1.0)$ & 80 & 50 & 66 & 0.40 & 1.6 & 3 \\
3 & $\mathrm{BSA}^{\mathrm{e}}$ & $\mathrm{Sc}(\mathrm{OTf})_{3}(1.4)$ & 40 & 70 & 84 & 0.67 & 1.8 & 0 \\
4 & $\mathrm{BSA}^{\mathrm{e}}$ & $\mathrm{Sc}(\mathrm{OTf})_{3}(0.7)$ & 40 & 70 & 87 & 0.66 & 1.7 & 0 \\
5 & $\mathrm{BSA}^{\mathrm{e}}$ & none & 40 & 70 & no polymerization & - & - & -1 \\
6 & $\mathrm{BAA}^{\mathrm{f}}$ & $\mathrm{Sc}(\mathrm{OTf})_{3}(0.7)$ & 40 & 90 & 78 & 0.85 & 2.1 & 0 \\
7 & $\mathrm{SA}^{2} \mathrm{BAA}^{\mathrm{g}}$ & $\mathrm{Sc}(\mathrm{OTf})_{3}(0.1)$ & 100 & 50 & 87 & 0.75 & 2.0 & 0 \\
\hline
\end{tabular}

${ }^{a}$ All runs are performed by bulk (melt) polycondensation under reduced pressure $(0.3-30 \mathrm{mmHg}) .{ }^{\mathrm{b}} \mathrm{After}$ reprecipitation using $\mathrm{CHCl}_{3}$ /diethyl ether. ${ }^{\mathrm{c}}$ Determined by SEC measurement in $\mathrm{CHCl}_{3}$ relative to poly(styrene). ${ }^{\mathrm{d}}$ Determined by ${ }^{1} \mathrm{H}$ NMR in $\mathrm{CDCl}_{3}$. ${ }^{\mathrm{e}}$ Bromosuccinic acid. ${ }^{\mathrm{f}} 2$-Bromoadipinic acid. ${ }^{\mathrm{g}}$ Ternary copolycondensation of SA and BBA $\left.\left([\mathrm{SA}]_{0} /[\mathrm{BBA}]_{0}=4 / 1\right]\right)$ with $1,4-\mathrm{BD}$.

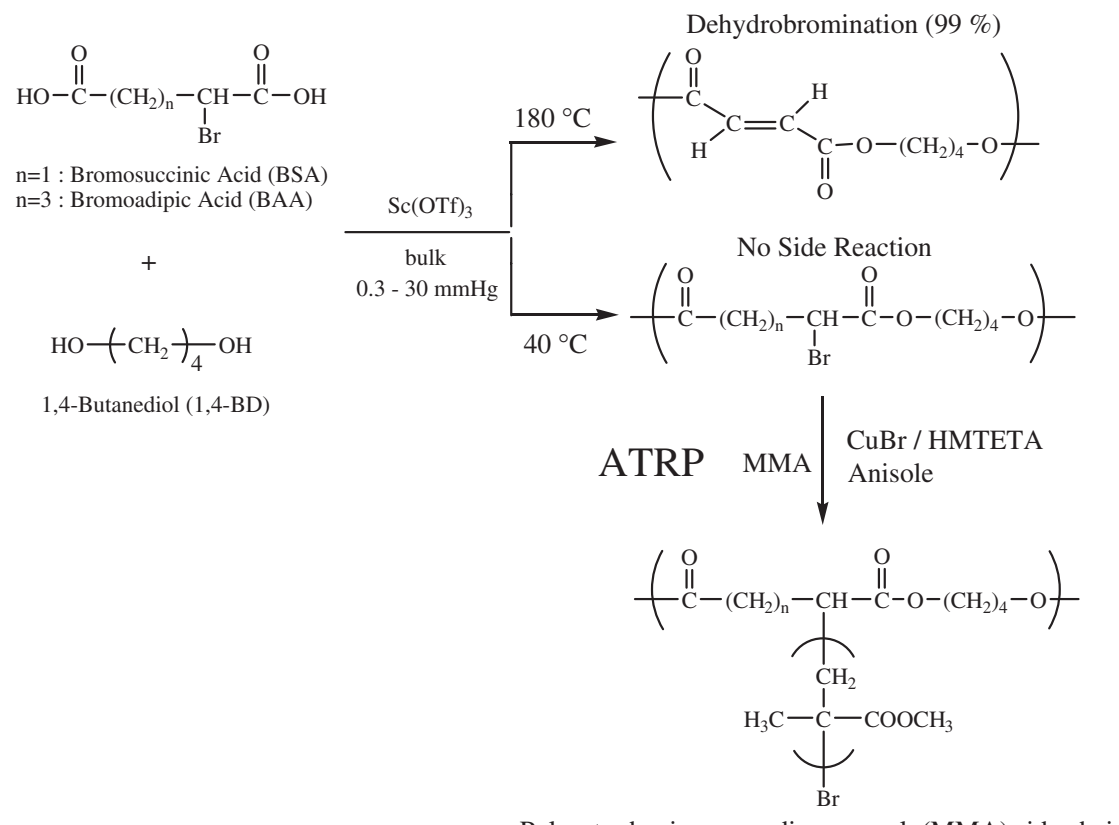

Polyester having monodisperse poly(MMA) side chains

Scheme 3. Synthesis of polyester having monodisperse poly(methyl methacrylate) side chains by combination of room-temperature polycondensation with ATRP.

confirmed by ${ }^{1} \mathrm{H}$ NMR and the peak assignment was established by comparison with that reported in previous report. ${ }^{11}$ The polycondensation with $1,4-\mathrm{BD}$ was carried out at $60^{\circ} \mathrm{C}$ for $120 \mathrm{~h}$ using $1.0 \mathrm{~mol} \%$ of $\mathrm{Sc}(\mathrm{OTf})_{3}$. While the polycondensation at $160^{\circ} \mathrm{C}$ without catalyst would result in isomerizations (Z- to $E$ and citraconic acid to itaconic acid) and gelation, ${ }^{11}$ linear polyester $\left(M_{\mathrm{n}}=1.41 \times 10^{4}\right)$ was obtained in this system. In the ${ }^{1} \mathrm{H}$ NMR spectrum, any peaks ascribed to isomerizations ( $E$-configuration: 2.29 and $6.81 \mathrm{ppm}$; itaconic acid unit: $3.37,5.77$, and $6.36 \mathrm{ppm}$ ) and gelations $(2.5-3.0 \mathrm{ppm})$ were not observed.

Room-temperature polycondensations of bromosuccinic acid (BSA) (at $40^{\circ} \mathrm{C}$ ) and 1,4-butanediol (1,4$\mathrm{BD})$ were performed under reduced pressure $(0.3-30$ $\mathrm{mmHg}$ ) using $\mathrm{Sc}(\mathrm{OTf})_{3}$ to give PBBS with $M_{\mathrm{n}}=$ $0.67 \times 10^{4} \quad\left(M_{\mathrm{w}} / M_{\mathrm{n}}=1.7_{7}, 84 \%\right.$ yield) (run 3 in Table III). At $180^{\circ} \mathrm{C},>99 \%$ dehydrobromination oc- curred and the obtained polyester hardly contains the bromo functionality (run 1). At $80^{\circ} \mathrm{C}$, the dehydrobromination was suppressed within $3 \%$ although the $M_{\mathrm{n}}$ is lower $\left(0.4 \times 10^{4}\right)$. As we confirmed no polycondensation in the absence of $\mathrm{Sc}(\mathrm{OTf})_{3}$, this polycondensation system is suitable for polycondensation of dicarboxylic acid having bromo functionality as well as carboncarbon double bond. Polycondensation of BBA also afforded the expected polyester without dehydrobromination (run 6). Ternary copolycondensation of SA and BAA with 1,4-BD was carried out in order to control bromo content $\left([\mathrm{SA}]_{0} /[\mathrm{BAA}]_{0}=4 / 1\right)$. The resulting polyester was characterized by IR and NMR measurements. From the ${ }^{1} \mathrm{H}$ NMR relative peak intensity ratio, the molar ratio of $[\mathrm{SA}] /[\mathrm{BAA}]$ in the copolyester was $4 / 1$, which coincided with the feed the ratio $\left([\mathrm{SA}]_{0} /[\mathrm{BAA}]_{0}\right)$. 

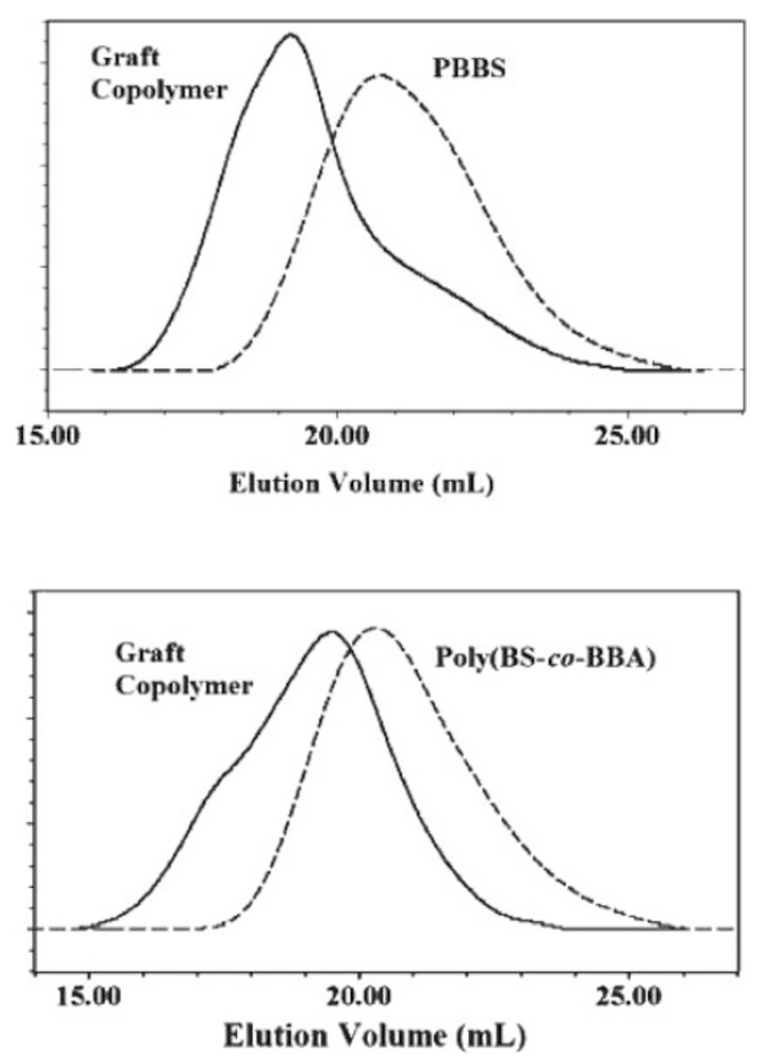

Figure 2. SEC traces of graft copolymers prepared by grafting MMA from PBBS (top) and poly(BS-co-BAA) (bottom) as macroinitiators.

Grafting of MMA from Polyester Containing Pendant Bromo Functionality Using ATRP Technique

As shown in Scheme 3, the ATRP of MMA ([M $]_{0} /$ $\left[\mathrm{I}_{0}=10\right)$ using PBBS $\left(M_{\mathrm{n}}=0.67 \times 10^{4}, M_{\mathrm{w}} / M_{\mathrm{n}}=\right.$ 1.8 , run 3 in Table III) as the macroinitiator and complex of $\mathrm{CuBr}$ and HMTETA ${ }^{12 \mathrm{a}}$ as the catalyst was carried out in anisole at $60^{\circ} \mathrm{C}$ for $10 \mathrm{~h}$ under nitrogen atmosphere to give polyester having PMMA side chains $\left[M_{\mathrm{n}}=1.42 \times 10^{4}\right.$ and $M_{\mathrm{w}} / M_{\mathrm{n}}=2.0$, $55 \%$ yield (trunk base)]. The structure was confirmed by IR and ${ }^{1} \mathrm{H}$ NMR measurements. The SEC trace shows an expected shift to higher molecular weight region compared with parent polyester having pendant active bromo groups as shown in Figure 2 (top). These results revealed that PBBS prepared by roomtemperature polycondensation acted as a macroinitiator. Using poly(BS-co-BAA) as the macroinitiator, ATRP of MMA also occurred (at $80^{\circ} \mathrm{C}$ for $10 \mathrm{~h}$ ). The SEC trace shifted to high molecular region after ATRP and the peak corresponding to parent copolyester was not confirmed (Figure 2, bottom). The initiator efficiency and DP of MMA side chain were calculated to be $43 \%$ and 16 (68\% conversion), respectively, from the ${ }^{1} \mathrm{H}$ NMR analysis.

In this paper, we demonstrated the room-temperature direct esterification of a carboxylic acid and alcohol catalyzed by $\mathrm{Sc}(\mathrm{OTf})_{3}, \mathrm{Sc}\left(\mathrm{NTf}_{2}\right)_{3}$, and polymer- supported scandium catalyst (PS-Sc). This breakthrough made it possible to synthesize aliphatic polyesters $\left(M_{\mathrm{n}}>1.0 \times 10^{4}\right)$ by room-temperature polycondensation. All the catalysts could be recycled for the polyester synthesis. The development of polycondensations at lower temperature is extremely effective for not only for environmentally friendly processes but also for advanced material design using monomers having chirality, functionality, and biological activity.

Acknowledgment. This work was funded by the Ministry of Education, Culture, Sports, Science and Technology of Japan (Grant-in-Aid for Development Scientific Research, No. 16750095). Additional support came from The Naito Research Grant and Nagoya Institute of Technology research promotion program to A.T.

\section{REFERENCES}

1. a) R. W. Lenz, Adv. Polym. Sci., 107, 1 (1993).

b) V. V. Koeshak and S. V. Vinogradora, "Polyester," Pergamon Press, New York, N.Y., 1995.

2. a) W. H. Carothers and G. L. Dorough, J. Am. Chem. Soc., 52, 711 (1930).

b) E. Takiyama, I. Niikura, and Y. Hatano, Japan Patent (1992).

c) M. Miura, H. Watanabe, and M. Fujiwara, Japan Patent, 53695 (1995).

d) H. Ito, N. Yamamoto, F. Hiroji, and M. Jojima, Japan Patent 71641 (1997).

3. a) H. Tanaka, Y. Iwanaga, G.-C. Wu, K. Sanui, Y. Kishimoto, and N. Ogata, Polym. J., 14, 643 (1982).

b) F. Higashi, Y. Yamada, and A. Hoshio, J. Polym. Sci., Polym. Chem. Ed., 22, 1653 (1984).

c) in situ activation: J. S. Moore and S. I. Stupp, Macromolecules, 23, 65 (1990).

4. a) M. Ajioka, K. Enomoto, K. Suzuki, and A. Yamaguchi, Bull. Chem. Soc. Jpn., 68, 2125 (1995).

b) Ni: M. Mochizuki, K. Mukai, K. Yamada, N. Ichise, S. Murase, and Y. Iwaya, Macromolecules, 30, 7403 (1997).

c) $\mathrm{HfCl}_{4}\left(\mathrm{THF}_{2}\right)$ : K. Ishihara, S. Ohara, and H. Yamamoto, Science, 290, 1140 (2000).

d) Sn distannoxane: M. Ishii, M. Okazaki, Y. Shibasaki, and M. Ueda, Biomacromolecules, 2, 1267 (2001).

e) Ti: M. Ikeno and K. Kawamoto, Japan Patent 36489 (1998).

f) lipase: H. Uyama, K. Inada, and S. Kobayashi, Polym. J., 32, 440 (2000).

5. a) S. Kobayashi, I. Hachiya, and Y. Yamanoi, Bull. Chem. Soc. Jpn., 67, 2342 (1994).

b) S. Kobayashi, S. Nagayama, and T. Busujima, J. Am. Chem. Soc., 120, 8287 (1998).

c) N. Nomura, A. Taira, and M. Okada, Macromolecules, 33, 1497 (2000).

6. a) A. Takasu, Y. Oishi, Y. Iio, Y. Inai, and T. Hirabayashi, Macromolecules, 36, 1772 (2003).

b) A. Takasu and T. Hirabayashi, Japan Patent, 306535 
(2003).

c) A. Takasu, Y. Oishi, Y. Iio, Y. Inai, and T. Hirabayashi, Polym. Prepr. (Am. Chem. Soc., Div. Polym. Chem.), 44(2), 629 (2003).

d) A. Takasu, Y. Iio, Y. Oishi, Y. Narukawa, and T. Hirabayashi, Macromolecules, 38, 1048 (2005).

7. a) Polythioamide: K. Sanui, Y. Kishimoto, and N. Ogata, Polym. J., 2, 422 (1971).

b) Polyamide: K. Sanui, T. Asahara, and N. Ogata, N. J. J. Polym. Sci., Part A: Polym. Chem., 7, 889 (1969).

8. E. K. Starostin, A. A. Mazurchik, A. V. Ignatenko, and G. I.
Nikishin, Synthesis, 10, 917 (1992).

9. K. Ishihara, M. Kubota, and Y. Yamamoto, Synlett, 265 (1996).

10. S. Nagayama and S. Kobayashi, Angew. Chem. Int. Ed., 39, 567 (2000).

11. As an example, see: S. Takenouchi, A. Takasu, Y. Inai, and T. Hirabayashi, Polym. J., 33, 746 (2001).

12. a) J. Xia and K. Matyjaszewski, Macromolecules, 30, 7697 (1997).

b) S. Lenoir, R. Riva, X. Lou, C. Detrembleur, R. Jerome, and P. Lecomte, Macromolecules, 37, 4055 (2004). 